\title{
Ontario Hospital Association proposes to scuttle privileges model for doctors
}

Published at www.cmaj.ca on June 1

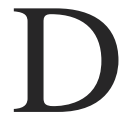

octors fear new hospital bylaws released by the Ontario Hospital Association (OHA) are aimed at reducing their decision-making authority over patients and eliminating the current privileging model by which doctors practise in the province's hospitals.

In a recent bulletin, Ontario Medical Association president Dr. Mark MacLeod stated that the OHA's new bylaws "contain several measures that would minimize physician input and influence in the decision-making process at hospitals."

MacLeod added that the changes “align with the OHA's recent public calls for the Public Hospitals Act to be reviewed and efforts to remove the privileges model from Ontario's hospitals in favour of contracts, which may prevent physicians from advocating for their patients."

In a later interview, MacLeod indicated the association is concerned that the bylaws will undermine the privileges model that "has been in existence for decades. It extends beyond mere contracts and provides physicians with legislated protections for due process. That means physicians have recourse if hospitals arbitrarily decide to change the 'contract' between physicians and the hospitals."

Under the current model, physicians can apply annually for privileges to practise in a hospital and a medical advisory committee makes recommendations to the hospital's board on whether or not to grant those privileges. An applicant will receive written notice of the committee's recommendation and can request a formal hearing before the board to present evidence against the recommendation.

If a physician is unhappy with the board's final decision, or if the board cancels, suspends or substantially alters a doctor's hospital privileges, they have a right of appeal to both the Health Professions Appeal and Review Board and the Divisional Court.

A spokeperson says that the medical association doesn't know what a contract model might look like because the OHA has only begun to look at the

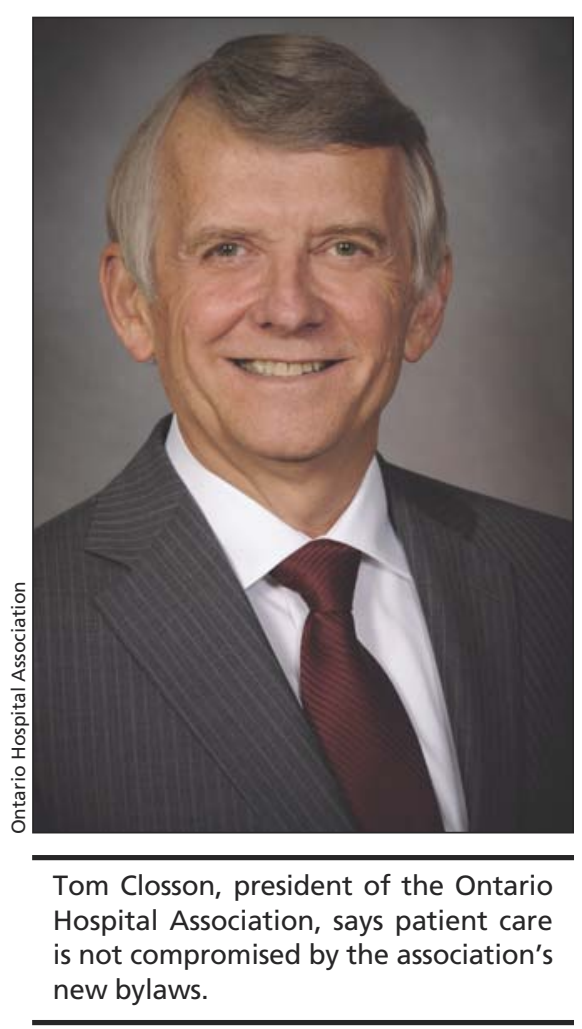

issue. But the association fears it would erode the protections physicians presently have in law.

While there is nothing in the new OHA bylaws that directly speaks to removing the current privileging model, the Ontario Medical Association sees the new stipulation that doctors cannot engage in any conduct that would adversely affect a hospital's "reputation or standing in the community" as part of a broader shift to reduce their roles and increase the power of hospital administrators (www.oha .com/KnowledgeCentre/Library/Tool
kits/Documents/FINAL\%20BOARD -APPOINTED\%20PROFESSIONAL\% 20STAFF\%20BY-LAW\%20(2010).doc).

Under the new bylaws, doctors must raise all concerns through proper channels, including the hospital's chief executive office and board of directors. Physicians who fail to comply with the new bylaws face suspension of their hospital privileges.

Earlier this spring, OHA president and CEO Tom Closson wrote in a letter to the Windsor Star that "the Public Hospitals Act and its physician 'privileges' system is keeping hospitals and physicians from working together to maximum potential because it isn't based on strong two-way accountability" (www.windsorstar.com/news /Hoping+build+strong+relationship /2719049/story.html).

"In rare instances where the quality of a physician's care is in serious question, the system is weighted toward protecting a physician's 'right' to practice. If a medical staff and hospital believe so strongly that the privileges of a physician need to be revoked, the physician and hospital instead face a multi-year legal process that is adversarial, complicated and very expensive," Closson added in the letter.

The OHA added in a recent statement that they believe it is reasonable for hospital boards to request physicians to pay proper consideration to the reputation of a hospital in return for the ability to access its resources (www .oha.com/NEWS/MEDIACENTRE /Pages/StatementfromtheOntarioHospital AssociationreGlobeandMailStoryon HospitalPrototypeBylaws.aspx).

But MacLeod says a doctor's primary concern should be making decisions based on what's best for patient care, not what's best for a hospital's reputation. "We know that patients expect their doctors to be able to advocate for them both inside and outside the hospital when it is necessary," he says. 
Closson says the bylaw don't compromise patient care.

"We absolutely share the sentiment that physicians should place the care of a patient as their number one priority. The new prototype bylaws do not change this," he says, adding that the intent of the bylaws is to encourage closer cooperation and collaboration between physicians and other hospital staff and employees.
MacLeod, though, notes that such collaboration and collegiality were undermined during the process of drafting the bylaws. "This is the first time in 60 years that the Ontario Medical Association was not involved in the development of the prototype bylaws. Ontario's doctors see this as a breakdown in the collaborative process."

Closson counters that the OHA sought the collaboration of the medical association, but when talks broke down, felt that updating the bylaws was too important to delay.

The OHA represents the province's 155 hospitals, some of which are already working to implement the new bylaws. Hospital adoption of the bylaws is voluntary. — Lauren Vogel, CMAJ

DOI:10.1503/cmaj.109-3273 